\title{
Experimental Study on the Effect of Humidification on the Pollution Characteristics of Particulate Matter in the Office
}

\author{
Yuefen Gao, Shanshan Nan, Guozhong Zheng, Tingting Gao \\ Department of Built Environment and Energy Application Engineering, North China Electric Power University, Baoding, China \\ Email:gaoyuefen@163.com
}

How to cite this paper: Gao, Y.F., Nan, S.S., Zheng, G.Z. and Gao, T.T. (2016) Experimental Study on the Effect of Humidification on the Pollution Characteristics of Particulate Matter in the Office. Journal of Environmental Protection, 7, 1791-1801. http://dx.doi.org/10.4236/jep.2016.712143

Received: October 13, 2016

Accepted: November 11, 2016

Published: November 14, 2016

Copyright (c) 2016 by authors and Scientific Research Publishing Inc. This work is licensed under the Creative Commons Attribution International License (CC BY 4.0).

http://creativecommons.org/licenses/by/4.0/ (c) (i) Open Access

\begin{abstract}
Indoor air quality has a direct impact on human health. Indoor air quality has aroused great concern. This experimental study compares the effects of different water humidification on the indoor particulate pollution characteristics, and analyzes the mass concentration and the particulate number concentration distribution of different sizes of particulates with time under each condition of the purified water humidification, the tap water humidification and the cold boiled water humidification in the office. The results show that under the three kinds of wetting conditions, the concentration of the fine particulates is higher. More minerals are contained in the tap water and the cold boiled water, so the two kinds of humidification have more significant impact on indoor particulate matter. But the purified water humidification has nearly no significant effect on it. The calcium and magnesium ionic compounds are partly removed after the water boiled, so the cold boiled water humidification has less impact on the indoor particulate matter than the tap water humidification. The mass concentration and particulate number concentration of the particle may also be affected due to the frequency of ultrasonic vibration.
\end{abstract}

\section{Keywords}

Humidification, Particulate Matter, Pollution Characteristics, Particulate Mass Concentration, Particulate Number Concentration

\section{Introduction}

Nowadays, people spend more than $80 \%$ of their time in room [1]. The particulate concentration and particulate size distribution of indoor air have more significant impact on human health. High particulate matter concentration in the air will damage the 
respiratory system [2], and cause cardiovascular disease and cancer [3] [4]. Mineral particulates may lead to the damage of infant nerve development and neurological dysfunction [5]. Many studies have concluded that residents suffer the increase of morbidity and mortality after a long-term or a short-term exposure in the atmosphere [6] [7] [8]. The smaller the particulate size, the deeper part the particulate matter may enter into human body [9]. The fine particulates with a diameter less than $2.5 \mu \mathrm{m}$ can enter into the bronchus and other lower respiratory system, even into the lungs and blood circulation system, then they are transported to all parts of the human body through the blood circulation [10]. PM2.5 possesses larger specific surface area than PM10. It can carry more toxic and harmful substances to the deeper parts of the body, which is more harmful for the human health [11] [12]. Correlational researches show that cooking, cleaning and smoking are the main pollution sources in the residential buildings [13] [14] [15].

A recent study showed that coagulation phenomenon occurred in the fine particulates with the indoor relative humidity increasing. The greater the relative humidity was, the coagulation phenomenon was more obvious [16]. But, the effect of different wetting water quality on indoor particulate matter is rarely reported. If the wetting water has different quality, the particulates entering the air may have different level. The pollution characteristics and dynamic changes of indoor particulate matter in different water quality need to be studied.

\section{Experiment on the Effect of Humidification on the Pollution Characteristics of the Particulate Matter}

\subsection{Experimental Scheme}

The experiment is carried out in an office on the third floor. The area of the office is about $39 \mathrm{~m}^{2}$, as shown in Figure 1. There are four windows on south side (outside) and a door on north side (interior). All the furniture in the office is wooden.

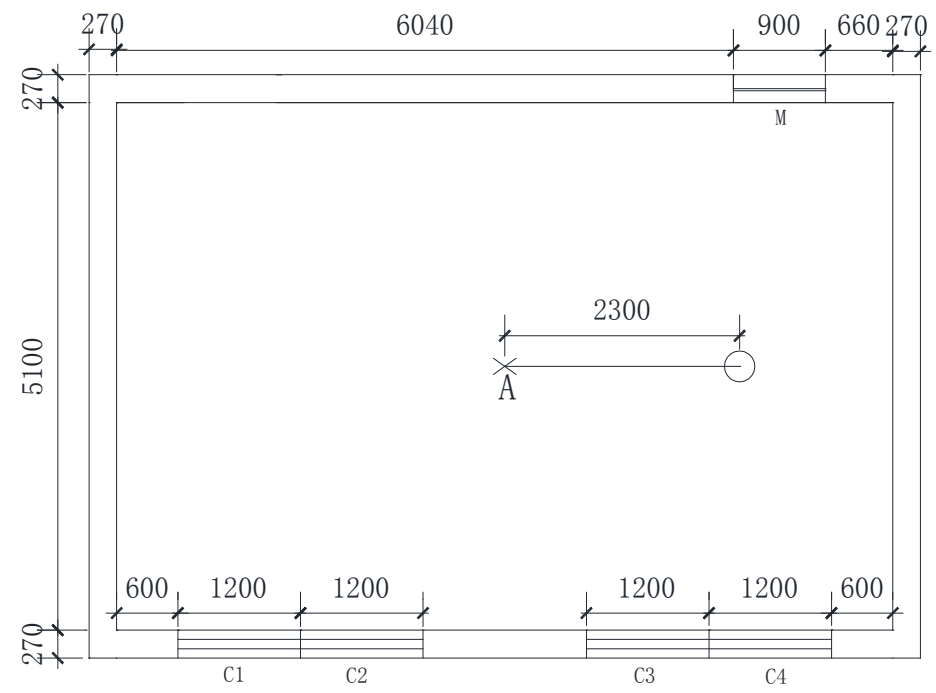

Figure 1. Schematic diagram of experimental site and measuring point. 
The humidification experiment is conducted in winter under three humidification modes of tap water, cold boiled water and purified water. Each humidification experiment lasts two hours and they keep the same humidification capacity. In the experiment, the sampling point (A) is located in the center of the room according to the diagonal principle. The height is $0.8 \mathrm{~m}$ from the ground [17].

\subsection{Experimental Apparatus and Measuring Method}

The particulate mass concentration of PM1, PM2.5 and PM10 is measured by the intelligent dust detector. The particulate number concentration of $0.3-1.0 \mu \mathrm{m}, 1.0-2.5 \mu \mathrm{m}$ and $2.5-10 \mu \mathrm{m}$ is counted by the laser particulate counter. The indoor relative humidity is tested by the multi-function parameter. A set of test data are recorded in every five minutes.

The intelligent dust detector and the laser particulate counter are placed in parallel on both sides of the sampling point. The ultrasonic humidifier is used to humidify the indoor air. It is placed on the desk from the sample point of $2.3 \mathrm{~m}$ at the same height. The schematic diagram of experimental site and measuring point is showed in Figure 1.

\section{Experimental Results and Discussion}

\subsection{Variation of Indoor Relative Humidity under Different Humidification Conditions}

Each humidification experiment lasts two hours and they keep the same humidification capacity.

Figure 2 shows the change of indoor relative humidity with time under the three conditions of purified water humidification, tap water humidification, and cold boiled water humidification. The growth trend of indoor relative humidity under the pure water humidification is similar to the tap water humidification. Under the cold boiled

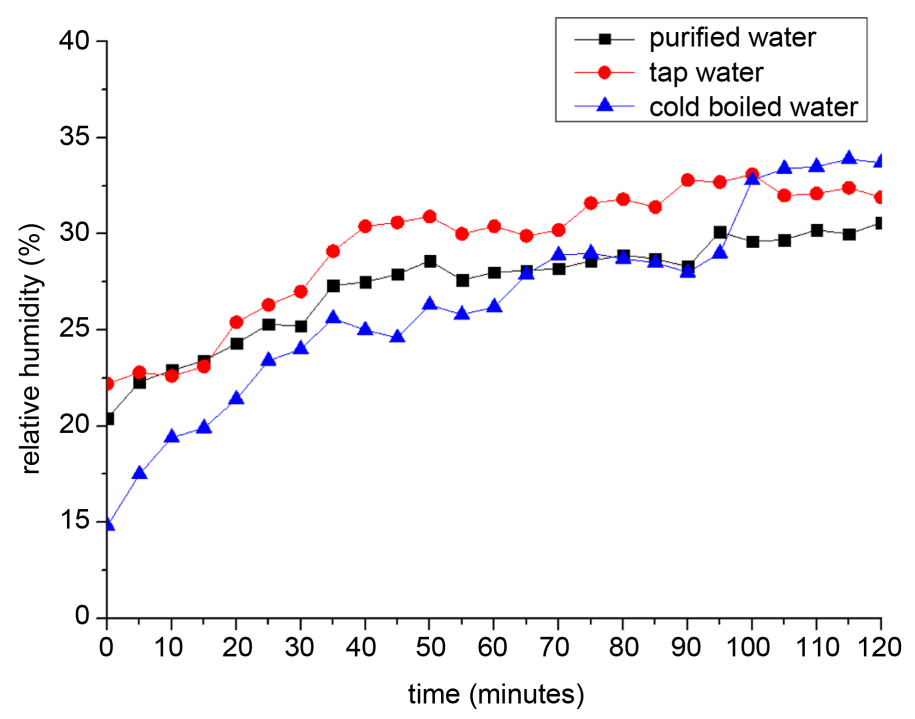

Figure 2. Indoor relative humidity varying with time under the three humidification conditions. 
water humidification, the initial value of the indoor relative humidity is lower, but at the end of the humidifying, the indoor relative humidity under the three conditions is nearly the same.

\subsection{Variation of Particulate Mass Concentration under Different Humidification Conditions}

\subsubsection{Change Curves of Mass Concentration of PM1, PM2.5 and PM10 with Humidification Time under Different Humidification Conditions}

The change curves of mass concentration of indoor PM1, PM2.5 and PM10 with humidification time under the three humidification conditions are shown in Figure 3.

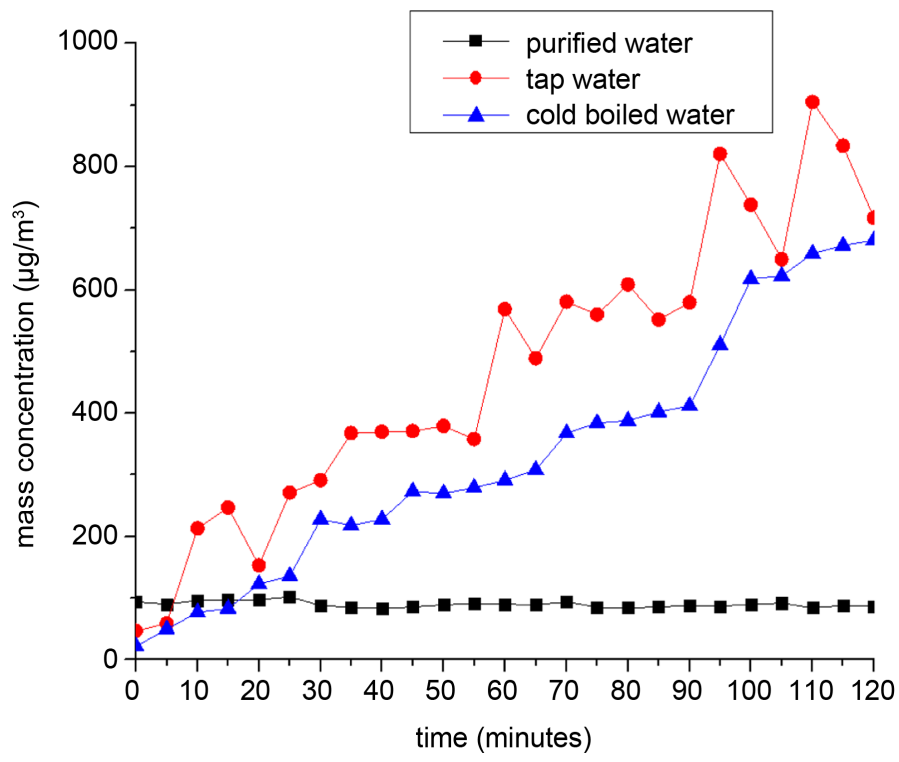

(a) PM1

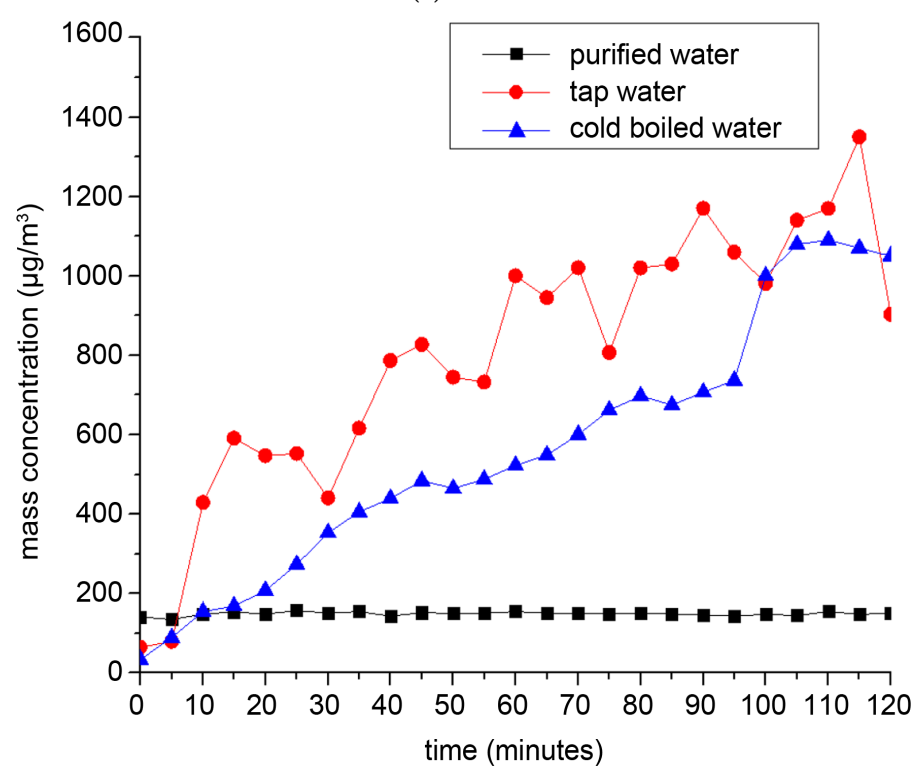

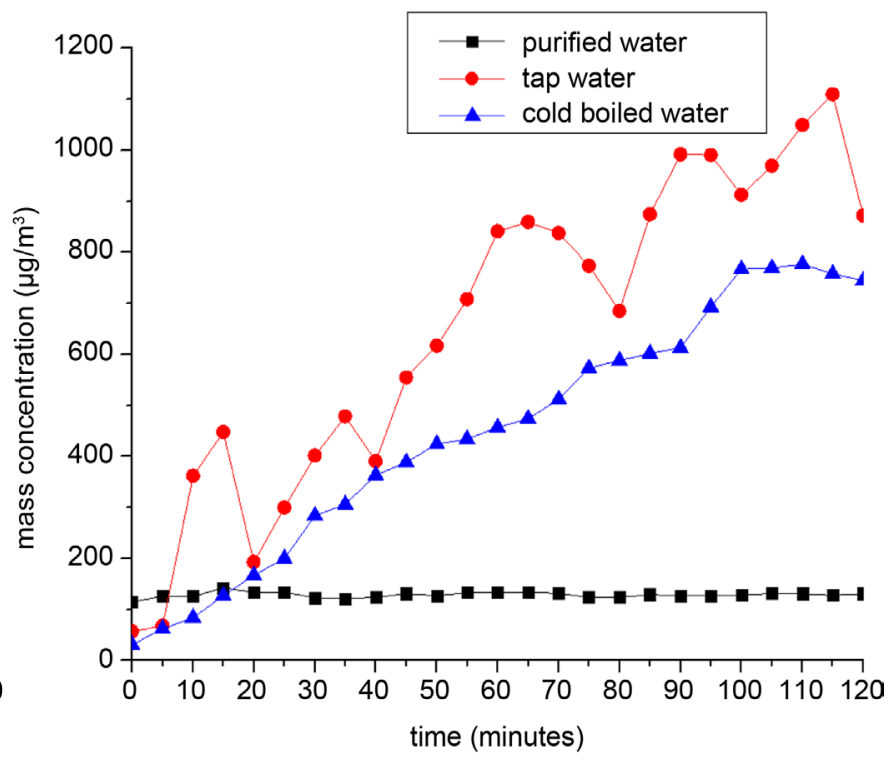

(b) PM2.5

(c) PM10

Figure 3. Change of the mass concentration with different particulate size with time under three humidification conditions. 
Under the condition of the tap water humidification and the cold boiled water humidification, the mass concentration of indoor PM1, PM2.5 and PM10 increases significantly. But the particulate mass concentration keeps at a relatively low value and the change of it is not obvious under the condition of the purified water humidification. This may be because that there are rarely little minerals and aqueous impurities. The mass concentration of the particulate matter increases slowly and smoothly under the condition of the cold boiled water humidification comparing with that under the tap water humidification. That is because that the calcium and magnesium ionic compounds are partly removed after the water boiled.

The mass concentration of particulate matter increases and fluctuates greatly under the condition of the tap water humidification. It may be due to the ultrasonic impact on the particulate matter.

\subsubsection{Effect on the Different Particulate Size Range under Different Humidification Conditions}

In order to further analyze the effect on the different particulate size range under different humidification conditions, the mass concentration of PM0.3 - PM1, PM1 PM2.5 and PM2.5 - PM10 is compared under the three conditions. The change curves of the particulate mass concentration with time with different particulate size range under the three conditions are shown in Figure 4.

Under the condition of the purified water humidification, the mass concentration of PM0.3 - PM1, PM1 - PM2.5 and PM2.5 - PM10 has little change and fluctuates in a small range.

Under the condition of the tap water humidification, the mass concentration fluctuates greatly for the three particulate size ranges. The concentration of PM0.3 - PM1 increases the most obviously. But the fluctuation range of PM1 - PM2.5 and PM2.5 PM10 is much remarkable. This indicates that the tap water humidification has a significant impact on the mass concentration of PM0.3 - PM1.

Under the condition of the cold boiled water humidification, the mass concentration of PM0.3 - PM1 increases sharply, the mass concentration of PM1 - PM2.5 grows slowly and shows a downward trend at the late stage of the experiment, the mass concentration of PM2.5 - PM10 changes gently and has a larger increase after 95 minutes. Thus, under the condition of the cold boiled water humidification, the change of mass concentration of PM0.3 - PM1 is the most obvious.

Figure 4 shows that PM0.3 - PM1 is the dominated particulate matters in the three kinds of humidification. Figure 4 also shows that the mass concentration of particulate matter increases and fluctuates greatly under the condition of the tap water humidification. It may be due to the ultrasonic impact on the particulate matter.

\subsubsection{Changes of the Different Size Particulate Mass Concentration with Time under Different Humidification Conditions}

In order to further study the influence of three humidification conditions on the particulate mass concentration of the same particulate size, the mass concentration with time of PM0.3 - PM1, PM1 - PM2.5, PM2.5 - PM10 under the humidification conditions 


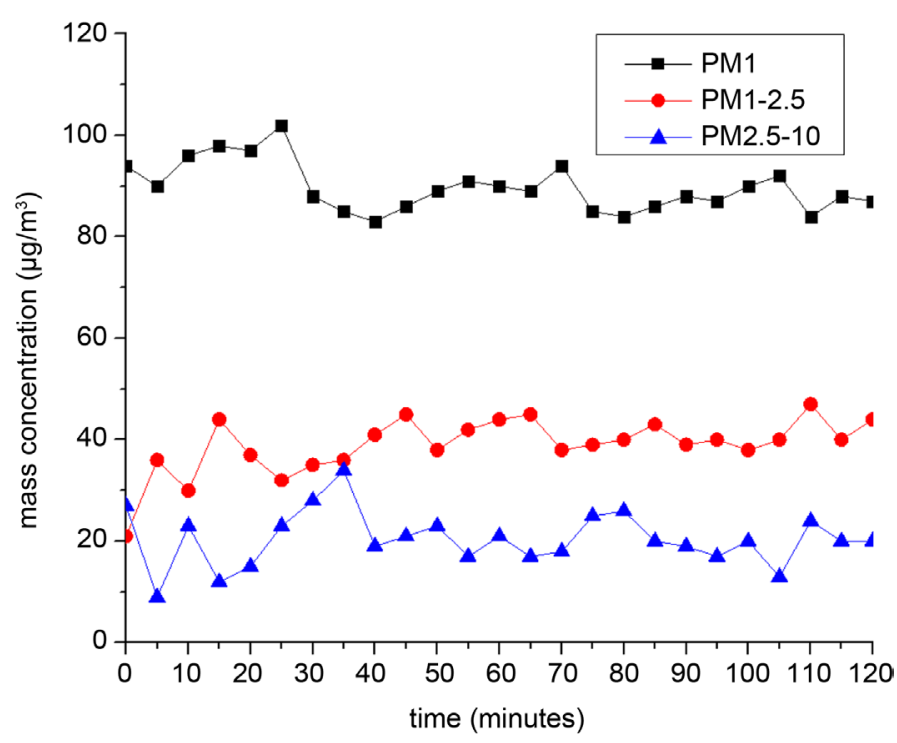

(a) Purified water

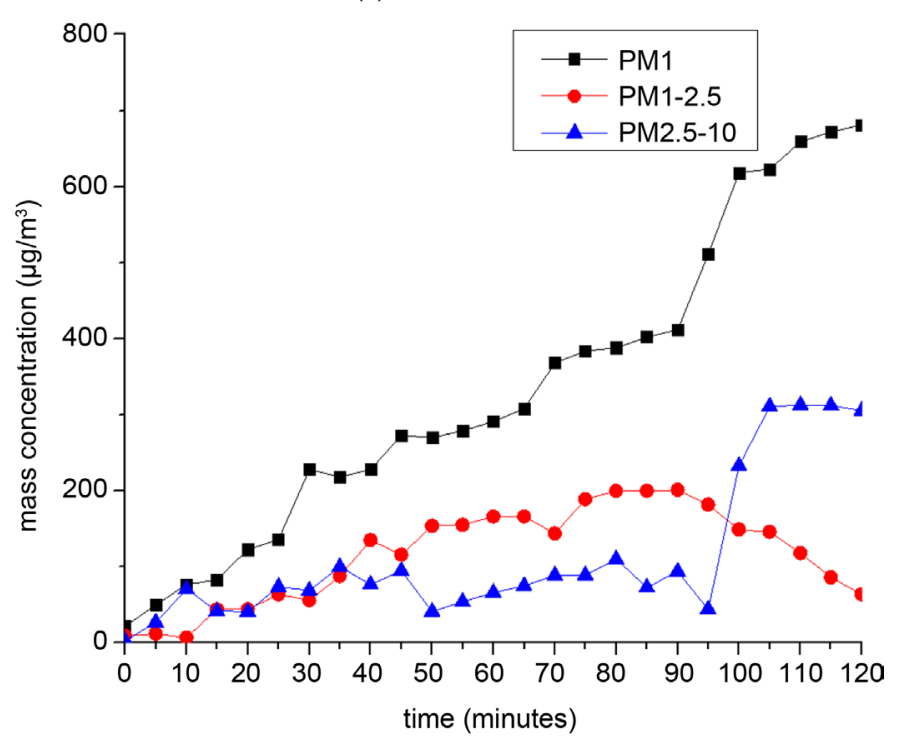

(c) Cold boiled water

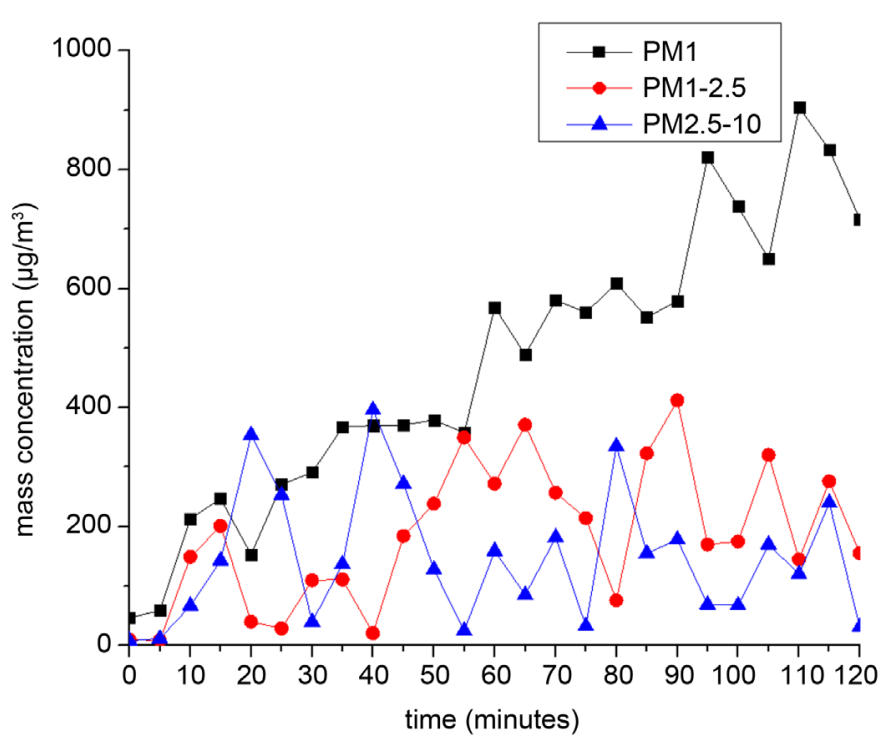

(b) Tap water

Figure 4. The change of the particulate mass concentration with time with different particulate size range under the three humidification condition.

is compared in Figure 5.

Under the condition of the purified water humidification, the mass concentration of PM0.3 - PM1 has almost no change. Under the conditions of the tap water humidification and the cold boiled water humidification, the mass concentration of PM0.3 - PM1 increases greatly. Under the condition of the tap water humidification, the mass condition of PM0.3 - PM1 increases remarkably. By analysis of the data under two humidification conditions, the largest increase of the mass condition of PM0.3 - PM1 is 858 $\mu \mathrm{g} / \mathrm{m}^{3}$ and $659 \mu \mathrm{g} / \mathrm{m}^{3}$ respectively. It can be seen that the effect of the cold boiled water humidification on the mass concentration of PM0.3 - PM1 is slightly less than that of the tap water humidification. But it is more than that of the purified water humidification. 


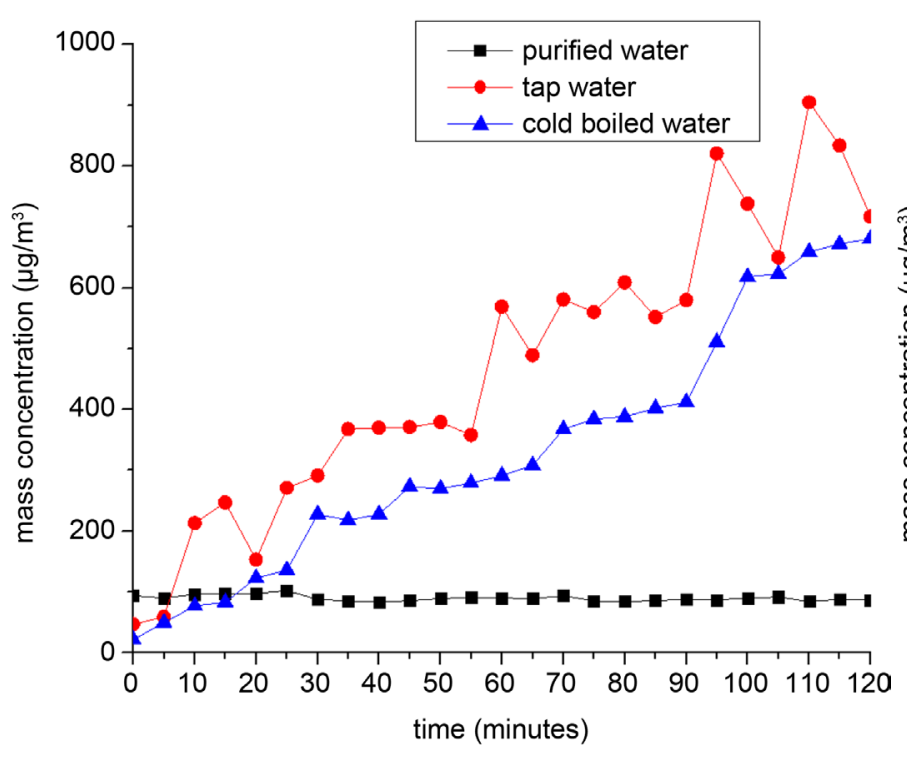

(a) PM0.3 - PM1

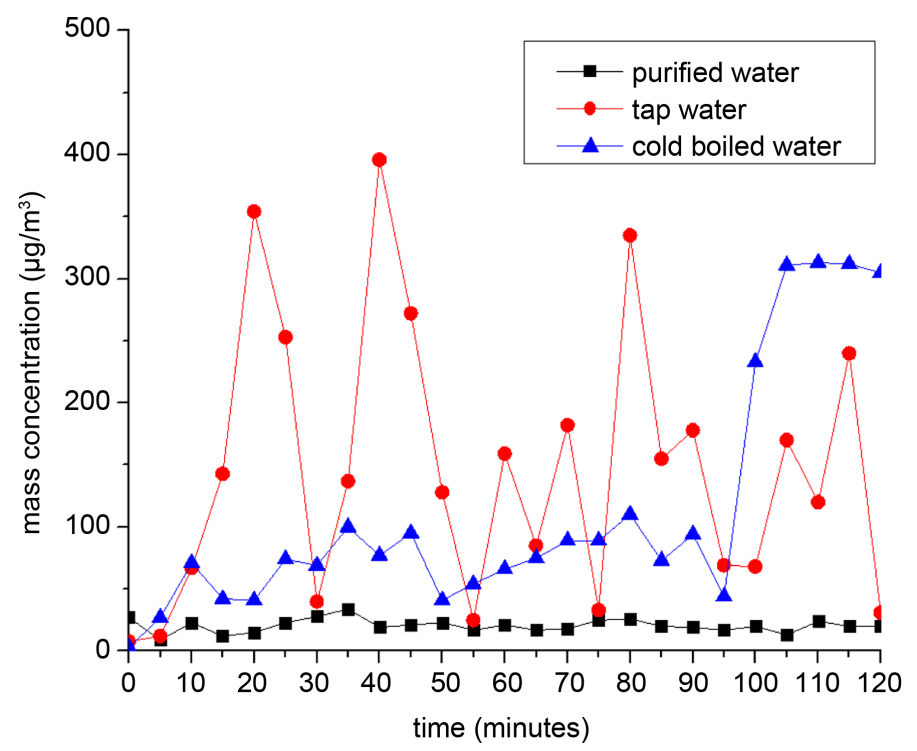

(c) PM2.5 - PM10

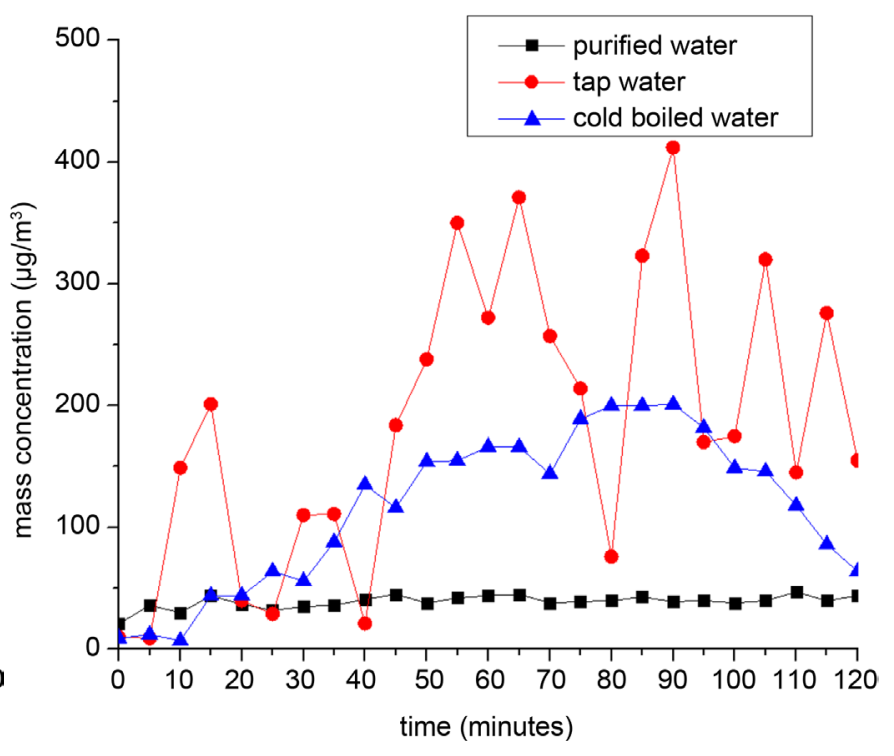

(b) PM1 - PM2.5

Figure 5. Change of the different size particulate mass concentrate with time under the three humidification conditions.

Under the condition of the purified water humidification, the mass concentration of PM1 - PM2.5 changes faintly. Under the condition of the tap water humidification, the mass concentration of PM1 - PM2.5 has a larger fluctuation, and the maximum value of $412 \mu \mathrm{g} / \mathrm{m}^{3}$ occurs at the 90th minute. It increases $402 \mu \mathrm{g} / \mathrm{m}^{3}$ compared to the initial value. Under the cold boiled humidification condition, the mass concentration of PM1 PM2.5 slowly increases at first. The maximum value reaches $201 \mu \mathrm{g} / \mathrm{m}^{3}$ at the 90 th minute. It increases $192 \mu \mathrm{g} / \mathrm{m}^{3}$ compared to the initial value. This shows that the mass concentration of PM1 - PM2.5 increases significantly under the tap water humidification condition.

Under the condition of the purified water humidification, the mass concentration of 
PM2.5 - PM10 has no obvious change. Under the condition of the tap water humidification, the mass concentration of PM2.5 - PM10 varies greatly. Under the condition of the cold boiled water humidification, the mass concentration of PM2.5 - PM10 has a minor fluctuation in the early stage of the experiment. And it does not increase obviously. But at the 95th minute of the experiment, there is an abrupt increase, reaching maximum value of $388 \mu \mathrm{g} / \mathrm{m}^{3}$. It increases $310 \mu \mathrm{g} / \mathrm{m}^{3}$ than the initial value. From the testing data, it can be concluded that the effect of the tap water humidification on the mass concentration of PM2.5 - PM10 is significantly higher than that of the cold boiled water humidification.

Comparing Figure 3 with Figure 5, the average concentration in each particulate size range is significantly less than that of maximum size particulate, as the smaller size particulate accounts for the major proportion.

\subsection{Variation of Particulate Number Concentration under Different Humidification Conditions}

The variation of particulate number concentration with humidification time of PM0.3 PM1, PM1 - PM2.5 and PM2.5 - PM10 under the three humidification conditions is shown in Figure 6.

From the number concentration distribution in Figure 6, we can see that PM0.3 PM1 is the dominated particulate matter. PM0.3 - PM1 has the 8 or 9 orders of magnitude, but PM1 - PM2.5 and PM2.5 - PM10 only have 5 orders of magnitude.

It also can be seen that under the condition of the purified water humidification, the particulate number concentration of PM0.3 - PM1 has a slightly downward trend. Under the conditions of the tap water humidification and the cold boiled water humidification, the particulate number concentration of PM0.3 - PM1.0 increases obviously. The particulate number concentration increasing range of the tap water humidification is much greater, reaching at $1.7 \times 10^{9} / \mathrm{m}^{3}$ after 120 minutes later, while it reaches at $1.1 \times$ $10^{9} / \mathrm{m}^{3}$ under the condition of the cold boiled water humidification. Thus, both the tap water humidification and the cold boiled water humidification can make the indoor particulate matter number increase sharply in a short time.

Under the condition of the purified water humidification, the particulate number concentration of PM1.0 - PM2.5 has a small amplitude fluctuation, and the maximum increase is only $1.1 \times 10^{5} / \mathrm{m}^{3}$. Under the condition of the tap water humidification, the particulate number concentration of PM1.0 - PM2.5 increases $3 \times 10^{5} / \mathrm{m}^{3}$ than the initial value at the end of the experiment, while the increase is $1.5 \times 10^{5} / \mathrm{m}^{3}$ under the condition of the cold boiled water humidification. Under the three humidification conditions, the particulate number concentration of PM1.0 - PM2.5 shows a downward trend in different ranges.

Under the condition of the purified water humidification, the particulate number concentration of PM2.5 - PM10 decreases more significantly. Under the condition of the tap water humidification, the particulate number concentration of PM2.5 - PM10 fluctuates slightly. Under the condition of the cold boiled water humidification, the 


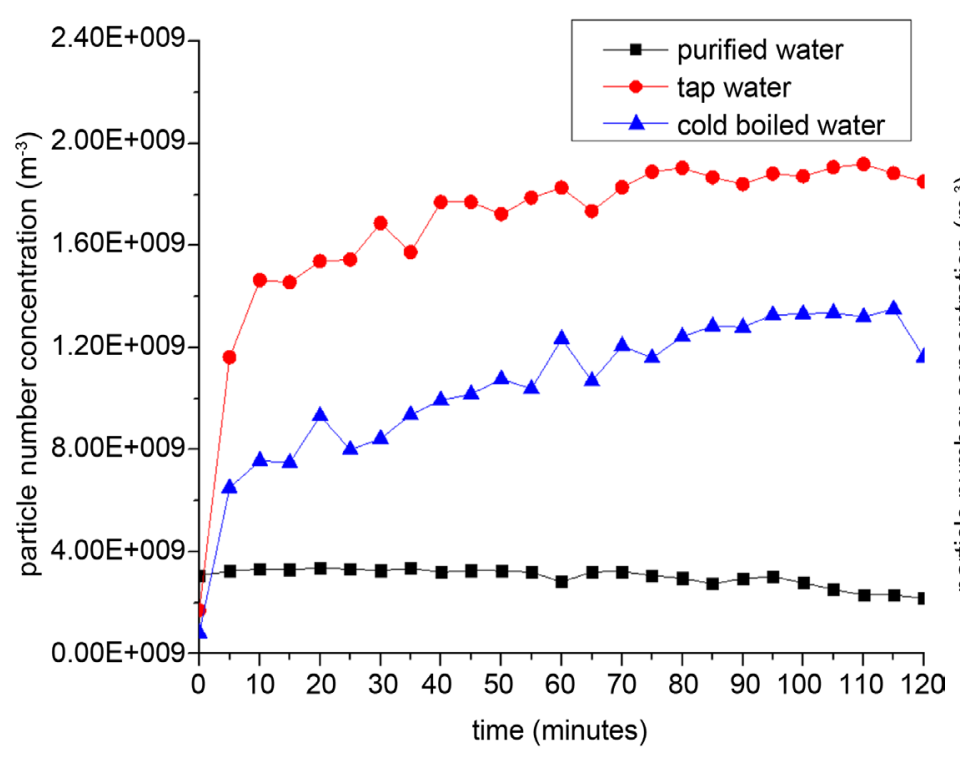

(a) PM0.3 - PM1

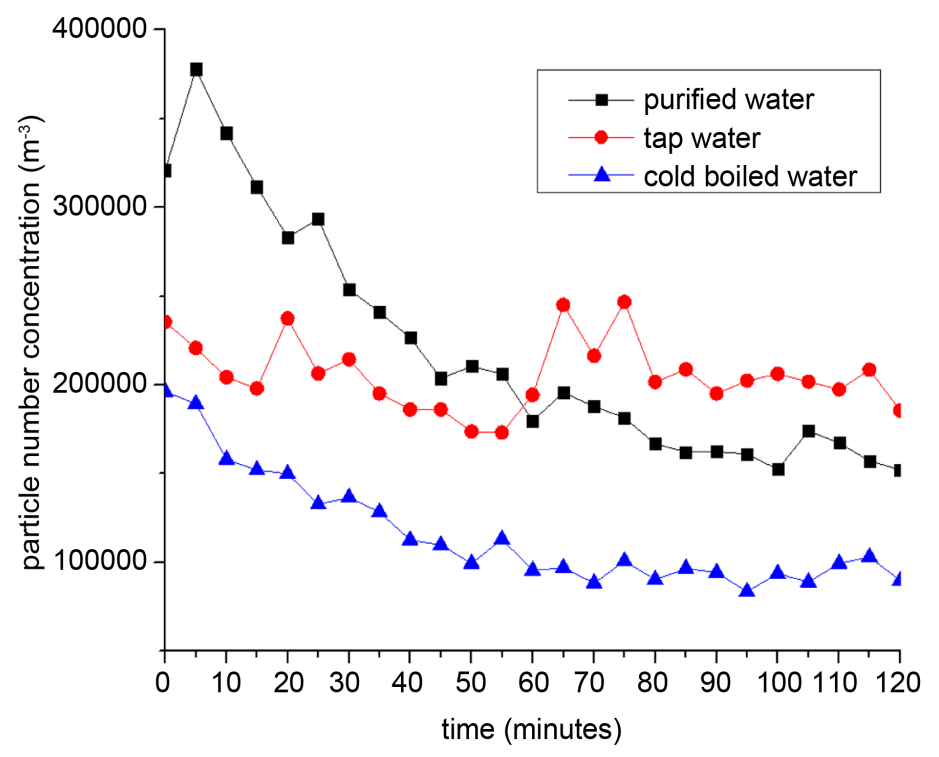

(c) PM2.5 - PM10



(b) PM1 - PM2.5

Figure 6. Change of the different particulate sizes number concentration with time under the three humidification conditions.

particulate number concentration of PM2.5 - PM10 declines slowly. At the end of the measurement, the particulate number concentration of PM2.5 - PM10 decreases $1.7 \times$ $10^{5} / \mathrm{m}^{3}, 5.0 \times 10^{4} / \mathrm{m}^{3}$ and $1.1 \times 10^{5} / \mathrm{m}^{3}$ respectively under the three humidification conditions.

All in all, under the two conditions of the tap water humidification and the cold boiled water humidification, the particulate number concentration of PM0.3 - PM1.0 increases significantly, and the fluctuation is much larger than that of PM1.0 - PM2.5 and PM2.5 - PM10. Thus, the tap water humidification and the cold boiled water humidification have the main effect on the particulate number concentration of PM0.3 PM1.0. 


\section{Conclusion}

The humidification experiment is conducted in winter under three humidification modes of tap water, cold boiled water and purified water. Each humidification experiment lasts two hours and they keep the same humidification capacity. The testing results show that the indoor relative humidity under the three humidification conditions is nearly the same at the end of the humidifying. Under the conditions of the tap water humidification and the cold boiled water humidification, the mass concentration of particulate matters increases dramatically. But under the condition of the purified water humidification, particulate matters of each particle size have no obvious changes, and the mass concentration is lower. Therefore, it is proved that the surge of particulate matter under the conditions of the tap water humidification and the cold boiled water humidification is mainly due to more minerals contained in the tap water and the cold boiled water. The mass concentration of particles increases more slowly under the condition of the cold boiled water humidification than that under the tap water humidification. The reason may be that the calcium and magnesium ionic compounds are partly removed after the water boiled. In spite of that, but the effect of the cold boiled water humidification on indoor particulate matter still cannot be ignored. Under the three kinds of wetting conditions, PM0.3 - PM1 is the dominated particulate matters in the three kinds of humidification. The number concentration of the fine particulates is much higher. The results also show that the frequency of ultrasonic vibration affects both the mass concentration and the particulate number concentration.

\section{Acknowledgements}

The authors express deep gratitude to the support of Fundamental Research Funds for the Central Universities: Study on the pollution characteristics and dynamic changes of indoor PM2.5 (Project No. 2014QN39).

\section{References}

[1] Monn, C. (2001) Exposure Assessment of Air Pollutants: A Review on Spatial Heterogeneity and Indoor/Outdoor/Personal Exposure to Suspended Particulate Matter, Nitrogen Dioxide and Ozone. Atmospheric Environment, 35, 1-32. http://dx.doi.org/10.1016/S1352-2310(00)00330-7

[2] Mar, T.F., Norris, G.A. and Koenig, J.Q. (2000) Associations between air Pollution and Mortality in Phoenix. Environmental Health Perspectives, 108, 347-353. http://dx.doi.org/10.1289/ehp.00108347

[3] Brook, R.D., Rajagopalan, S. and Pope, C.A. (2010) Particulate Matter Air Pollution and Cardiovascular Disease: An Update to the Scientific Statement from the American Heart Association. Circulation, 121, 2331-2378. http://dx.doi.org/10.1161/CIR.0b013e3181dbece1

[4] Susanne, S., Stefan, R., Clive, E., et al. (2015) Personal Exposure Monitoring of PM2.5 in Indoor and Outdoor Microenvironments. Science of the Total Environment, 508, 383-394. http://dx.doi.org/10.1016/j.scitotenv.2014.12.003

[5] Zhang, J. (1999) Research Progress on Long-Term Hazard and Mechanism of Lead Exposure during Development. Foreign Medical Sciences Section Hygiene, 26, 106-109. (In Chinese) 
[6] Dockery, D.W. (2009) Health Effects of Particulate air Pollution. Annals of Epidemiology, 19, 257-263. http://dx.doi.org/10.1016/j.annepidem.2009.01.018

[7] Kan, H., London, S.J., Chen, G., et al. (2008) Season, Sex, Age, and Education as Modifiers of the Effects of Outdoor Air Pollution on Daily Mortality in Shanghai, China: The Public Health and Air Pollution in Asia (PAPA) Study. Environmental Health Perspectives, 116, 1183-1188. http://dx.doi.org/10.1289/ehp.10851

[8] Venners, S.A., Wang, B., Xu, Z., et al. (2003) Particulate Matter, Sulfur Dioxide, and Daily Mortality in Chongqing, China. Environmental Health Perspectives, 111, 562-567. http://dx.doi.org/10.1289/ehp.5664

[9] Waldman, J.M, Lioy, P.J, Zelenka, M., et al. (1991) Wintertime Measurements of Aerosol Acidity and Trace Elements in Wuhan, a City in Central China. Atmospheric Environment, 25, 113-120. http://dx.doi.org/10.1016/0957-1272(91)90045-G

[10] Beckett, K.P., Freer, S.P. and Taylor, G. (2000) The Capture of Particulate Pollution by Trees at Five Contrasting Urban Sites. Arboricultural Journal, 24, 209-230. http://dx.doi.org/10.1080/03071375.2000.9747273

[11] Berico, M, Luciani, A. and Formignani, M. (1997) Atmospheric Aerosols in Urban Area Measurements of TSP and PMJO Standards and Pulmonary Deposition Assessments. Atmospheric Environment, 31, 3659-3665. http://dx.doi.org/10.1016/S1352-2310(97)00204-5

[12] Jones, A.P. (1999) Indoor Air Quality and Health. Atmospheric Environment, 33, 45354564. http://dx.doi.org/10.1016/S1352-2310(99)00272-1

[13] Cheng, H., Hu, M., Zhang, L.W., et al. (2009) PM2.5 Pollution Levels and Their Correlation in the Autumn of Beijing. Journal of Environment and Health, 26, 787-789. (In Chinese)

[14] Gui, F., Ye, Q.W., Zhou, Y.P., et al. (2013) Effect of Cleaning on Particle Concentration in Indoor Air. Journal of Anhui University of Technology, 30, 250-254. (In Chinese)

[15] Macintosh, D.L., Myatt, T.A., Ludwig, J.F., et al. (2008) Whole House Particulate Removal and Clean Air Delivery Rates for In-Duct and Portable Ventilation Systems. Journal of the Air \& Waste Management Association, 58, 1474-1482. http://dx.doi.org/10.3155/1047-3289.58.11.1474

[16] Li, C., Cui, S.X., Yang, W., et al. (2014) Experimental Study on the Effect of Relative Humidity on Particle Size Distribution of Fine Particles. Journal of Safety and Environment, 14, 254-258. (In Chinese)

[17] GB/T18883-2002 (2002) China Indoor Air Quality Standard. Standards Press of China, Beijing. (In Chinese) 
Submit or recommend next manuscript to SCIRP and we will provide best service for you:

Accepting pre-submission inquiries through Email, Facebook, LinkedIn, Twitter, etc. A wide selection of journals (inclusive of 9 subjects, more than 200 journals)

Providing 24-hour high-quality service

User-friendly online submission system

Fair and swift peer-review system

Efficient typesetting and proofreading procedure

Display of the result of downloads and visits, as well as the number of cited articles

Maximum dissemination of your research work

Submit your manuscript at: http://papersubmission.scirp.org/

Or contact jep@scirp.org 